\title{
OXYFINES Technique for Upgrading Zinc Containing Blast Furnace Sludge-Part 2: System Analysis
}

\author{
Katarina Lundkvist ${ }^{1, *}$, Sara Rosendahl ${ }^{1}$, Fredrik Nyman ${ }^{2}$, Kristofer Bölke ${ }^{2}$, \\ Lennart Gustavsson ${ }^{3}$, Daniel Söderström ${ }^{3}$ and Anita Wedholm ${ }^{3}$ \\ 1 Swerim AB, Box 812, SE-971 25 Luleå, Sweden; sara.rosendahl@swerim.se \\ 2 Linde Gas AB, SE-169 68 Solna, Sweden; fredrik.nyman@linde.com (F.N.); kristofer.bolke@linde.com (K.B.) \\ 3 SSAB Europe, SE-971 88 Luleå, Sweden; lennart.gustavsson@ssab.com (L.G.); \\ daniel.soderstrom@ssab.com (D.S.); anita.wedholm@ssab.com (A.W.) \\ * Correspondence: katarina.lundkvist@swerim.se; Tel.: +46-10-489-09-70
}

Received: 12 October 2020; Accepted: 26 October 2020; Published: 4 November 2020

\begin{abstract}
Integrating novel technology in production systems for the upgrading and further use of residual materials is a potential way of improving the resource efficiency. Assessing technology integration prospects, by performing system analysis, assists in the forecasting of effects and opportunities for different concepts. Based on pilot trials results, using Linde's OXYFINES technique for upgrading zinc containing blast furnace sludge, a system analysis was performed on the prospects of integrating an OXYFINES concept in an iron and steel production route. The calculations were made based on one option for a full-scale OXYFINES concept for indicating the effects on the blast furnace zinc load, raw material consumption, energy use and carbon dioxide emissions from using the OXYFINES sinter product as a raw material in blast furnace ironmaking or in the basic oxygen furnace steelmaking. The summarised system analysis results showed that the most advantageous metallurgical, environmental, and economic potential was realised in the calculations of using the sinter in the basic oxygen furnace. However, the sinter was found as well suitable for use in the blast furnace when considering mainly the metallurgical and the economic effects.
\end{abstract}

Keywords: system analysis; iron and steel production; OXYFINES integration; upgrading residuals

\section{Introduction}

Decreased residual materials generation and extending the recycling and utilisation has gradually become more important. The UN's Sustainable Development Goals and the European Commission's Circular Economy Package are promotors of the further strive for increased resource efficiency [1,2]. Avoiding landfill and making use of valuable contents of residual materials, thereby reducing the use of virgin raw materials entails positive effects on economy, space, and environment.

In ore-based steel production at the SSAB steel plant in Luleå, Sweden, blast furnace (BF) sludge is one residual currently put on landfill or long-term storage. Although, BF sludge contains substantial amounts of iron and carbon, all freshly generated sludge is deposited in settling ponds at the steel production site. The main reason for this is the zinc content in the sludge which due to process related restrictions makes it unsuitable for a direct recovery to the existing in-plant processes.

Zinc is an easily evaporated element, and therefore primarily follows with the process exhaust gases and is enriched in the dust/sludge formed in the gas purification system. Recovered dust and sludge is charged to the BF via a cold bonded briquette and by direct injection of recirculated BF dust to the $\mathrm{BF}$ As a result of the increased recycling of fine particulate residues, such as dusts from the in-plant off-gas purification systems, via the BF briquettes, the $\mathrm{Zn}$ content in generated BF sludge has increased [3]. A limit has been set for the BF permissible Zn-load, today $150 \mathrm{~g} / \mathrm{tHM}$. 
Separate treatment of residuals is for some cases considered to be more favourable, based on the prospects of more smooth-running primary processes and potential profits from higher-quality products which contributes to cover the costs of the residues processing [4,5]. A further advantage of a separate treatment is to consider the possibility to select a process option that produces material which in turn are suitable to be fed to the optimal unit in the primary production route. Increased quality of the residual materials is considered vital for improving the recovery rates whereby new technological solutions are proposed for achieving higher by-product qualities and hence increasing their utilisation in an environmental and economic sustainable way [6].

Linde has developed the OXYFINES technique which is suitable for upgrading fine particulate materials containing zinc, i.e., dust and sludge, and thereby generating usable products $[7,8]$. In the OXYFINES process the components such as zinc, sulphur and alkalis are vaporised at various degrees to a generated dust phase, whereas other non-gasifiable contents in the BF sludge, such as iron, forms an oxidic sinter phase in the bottom of the reactor.

In this research work, a system analysis was made based on promising results from performed pilot trials using OXYFINES technique for the recovery of BF sludge [9]. The results of the pilot trials showed a very stable, easily operated, and adjustable OXYFINES process with a zinc reduction rate of up to $97 \%$. The generated zinc dust was intended as a raw material in zinc production and the sinter product was intended for use as raw material in steel production, i.e., BF or basic oxygen furnace (BOF).

The sinter produced in the pilot trials was tested in the BOF steel production at SSAB in Luleå by charging the sinter to the BOF via the scrap chute as part of the cooling scrap. BOF steel and slag samples were analysed against reference and showed no quality effects. Thus, the OXYFINES sinter is considered possible for use as a raw material in the steel production (i.e., $\mathrm{BF}$ and $\mathrm{BOF}$ ).

A process integration model was used in this work to assess possibilities of implementing a full-scale OXYFINES concept to recover and upgrade BF sludge at the steel production site from a holistic point of view.

Generally, process integration is a term used for the application of system-oriented and integrated approaches to improve and optimise design and sustainability of industrial process plants. It is an effective tool used for systematic analyses and evaluations of potential process options and to provide strategies for efficient and economic resource saving solutions [10,11].

Common methods used in process integration are mathematical programming [12-15], pinch analysis, [16-18], material flow analysis [19-21] and lifecycle assessment [22-25]. The use of process integration methods for analysis and optimisation of material efficiency and recycling in steelmaking systems has expanded over the years promoting the use of a holistic view considering the synergy effects on the total system opposed to studying isolated solutions or single process view [26-33].

Methods like material flow analysis and lifecycle assessment is evolving with the increasing demand for realising circular flows and sustainability targets, since these requires knowledge and evaluations of total lifecycle impacts and overviews of the summarised effects in value chains.

Recent studies in the literature presents the application of combined process modelling, simulation, and optimisation tools for analysing the prospects of different process integration solutions for steelworks the integrated steelmaking cycle [34,35]. In one previous work, case studies with different scopes for the ore-based iron and steel production routes were presented [36]. The objective of the work was to exemplify how the use of process integration, through system analysis and optimisation, can assist in assessing the effects and opportunities in view of residues handling and increased material efficiency such as:

- Enhanced recovery of residual materials.

- Upgrading of residual materials to products.

- Specific elements recovery.

- Decreased use of virgin raw material. 
- Improved quality of residual materials.

- Decreased amounts of materials placed in long-term storage or landfills.

The prospects of a successful implementation of the OXYFINES concept are positive effects on sustainability, mainly by improved material efficiency and by waste prevention. The recovery of BF sludge decreases landfill and using the generated OXYFINES products contributes to the value chain by reduced need for virgin raw materials additionally affecting the system energy use and carbon dioxide $\left(\mathrm{CO}_{2}\right)$ emissions.

The system analysis calculations were made based on one option for a full-scale OXYFINES concept for indicating the effects on $\mathrm{BF}$ zinc load, raw material, energy and $\mathrm{CO}_{2}$ from using the OXYFINES sinter product as a raw material in BF ironmaking or alternatively in the BOF steelmaking. Furthermore, calculations were made for indicating a value of the OXYFINES sinter product when used in BF or in BOF, as well as for presenting a perspective on the sustainability aspects from possible effects on the system resource efficiency.

\section{Materials and Methods}

The process route in the SSAB Lulea system model is the ironmaking, consisting of BF and desulphurisation (deS), and the steelmaking including BOF and ladle metallurgy. Other associated parts essential in the specific analysis is the BF briquettes. The freshly generated BF sludge (i.e., with higher zinc content) is put in sludge pond deposit, and lesser parts of the old sludge in the ponds (i.e., with lower zinc content) is used in the BF briquette, Figure 1.

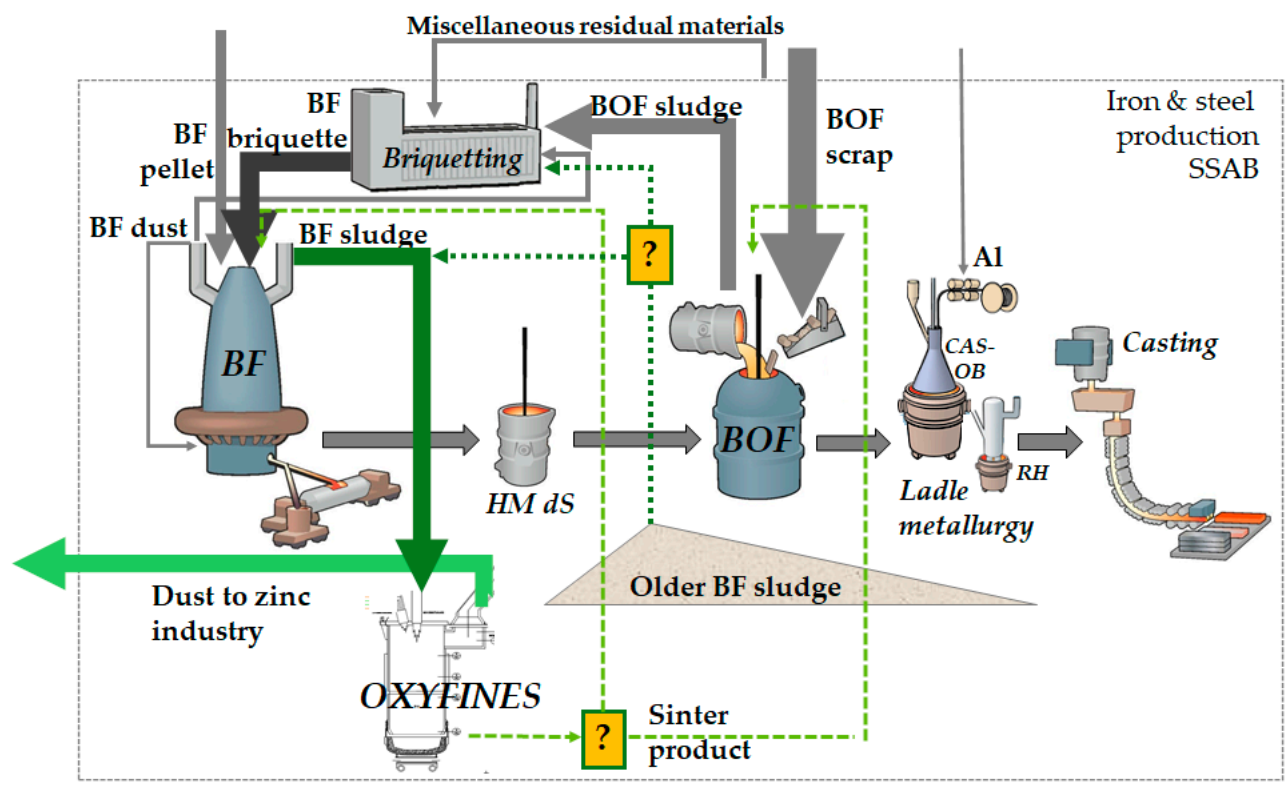

Figure 1. Schematics of the production system, and main zinc flow, including the OXYFINES concept.

The system analysis in this research work was made to indicate effects, both positive and negative, from using the OXYFINES sinter product as a raw material either in the BF iron making or in the steelmaking converter (BOF). The analysis included the effects on BF zinc load, on raw material consumption, energy, and $\mathrm{CO}_{2}$ in the $\mathrm{BF}$ and the $\mathrm{BOF}$ process units and in the system.

The system analysis and assessment of the process chain of using the OXYFINES sinter product, were carried out using a developed Excel spreadsheet model, "TOTMOD". The model is based on the spreadsheet model "Masmod", developed at SSAB, Luleå in Sweden during the 1980s, and for which the principles, design, and layout is previously presented in the literature [37]. The model is a 1-dimensional static model based on iterative heat and mass balances, including element distribution to, dust, sludge, slag, and metal. The model is used for process simulation and studies of various operating 
conditions as well as of the influence of specific process parameters. The model simulates the holistic effect on the process system considering raw materials use and quality of the final steel product, as well as the quality of generated residual materials (i.e., slag, dust, and sludge).

A reference scenario is used to set the specific calibration constraints required in the model. The model is calibrated for specific process conditions and a specific production period i.e., reference period via collected data from the production system in regard. The case study scenarios were evaluated against the reference scenario, based on average production data and operational reports from SSAB Luleå works. Collected reference data of the BF includes:

- Iron ore pellet mix $100 \%$.

- $\quad$ Pulverised coal injection (PCI) $135.5 \mathrm{~kg} / \mathrm{tHM}$ and BF dust injection $6.5 \mathrm{~kg} / \mathrm{tHM}$.

- Scrap charged $33.9 \mathrm{~kg} / \mathrm{tHM}$ and BF briquette amount $99.7 \mathrm{~kg} / \mathrm{tHM}$.

- $0.41 \%$ Silicon (Si) in hot metal (HM) (constant).

- $0.21 \%$ Manganese (Mn) (adjusted with Mn slag) in HM.

- $\quad 0.035 \%$ Phosphorus (P) (adjusted with BOF slag) in HM.

- $\quad$ BF slag rate $167 \mathrm{~kg} / \mathrm{tHM}$, slag basicity Bell's ratio 1.3 (B2: $\mathrm{CaO} / \mathrm{SiO}_{2}$ approx. 1.02).

- $\quad$ BF dust generation ca $20.9 \mathrm{~kg} / \mathrm{tHM}$ and BF sludge generation (dry weight) ca $5.5 \mathrm{~kg} / \mathrm{tHM}$.

Collected reference data of the BOF includes:

- Addition of OXYFINES sinter product primarily made by reducing the charged amount of iron ore pellet.

- $\quad$ Steel scrap $17.5 \%$ of liquid steel (LS) weight.

- Iron ore pellet $0.7 \%$ of LS weight.

- $\quad$ BOF slag rate $89.5 \mathrm{~kg} / \mathrm{tLS}$.

- Basicity: $\mathrm{B} 2\left(\mathrm{CaO} / \mathrm{SiO}_{2}\right)$ in $\mathrm{BOF}$ slag, 3.84 .

- Total BOF sludge (coarse and fine) generation (dry weight) ca $30.2 \mathrm{~kg} / \mathrm{tLS}$.

The system analysis calculations are on an annual HM production of $1993 \mathrm{ktonne}$ and LS production of 2100 ktonne, and OXYFINES processing of 24 ktonne BF sludge (wet weight, 50\% moisture content) resulting in 1.3 tonne sinter per hour and 0.231 tonne dust per hour.

The OXYFINES sinter production of 9360 tonne is in the system analysis evenly distributed during the annual production time either to the BF with $4.697 \mathrm{~kg} /$ tonne HM i.e., Scenario BF or to the BOF with $4.457 \mathrm{~kg} /$ tonne LS i.e., Scenario BOF, Table 1.

Table 1. System calculation basis with the integration of a full-scale OXYFINES unit.

\begin{tabular}{lc}
\hline Production & \\
\hline BF hot metal (HM) production (ktonne/a) & 1993 \\
BOF liquid steel (LS) production (ktonne/a) & 2100 \\
BF sludge, wet wt. (50\% moisture) (ktonne/a) & 24 \\
\hline OXYFINES Full Scale Unit & \\
\hline Annual operation time (h) & 8000 \\
90\% available operation time (h) & 7200 \\
Sludge processing, (50\% moisture) (tonne/h) & 3.400 \\
Carbon content in BF sludge (\%) & 24 \\
Sinter product (tonne/h) & 1.300 \\
Sinter product (tonne/a) & 9360 \\
Dust product (tonne/h) & 0.231 \\
\hline OXYFINES sinter to BF (kg/tHM)—Scenario BF & 4.697 \\
OXYFINES sinter to BOF (kg/tLS)—Scenario BOF & 4.457 \\
\hline
\end{tabular}


The approach to the case study calculations carried out were as follows:

- The scenarios for the analysis were made according to one OXYFINES concept for full scale plant, based on recovering and upgrading 12 ktonne of sludge/year (dry weight) corresponding to a sinter amount to BF of $4.697 \mathrm{~kg} /$ tonne HM in Scenario BF, and to BOF of $4.457 \mathrm{~kg} /$ tonne LS in Scenario BOF.

- Analysis were made of effects on the BF zinc load, on raw materials use and the total material efficiency. Further the calculations were made for indicating energy, $\mathrm{CO}_{2}$, and cost effects. The calculations of the OXYFINES sinter product value were based on average raw material prices. In the analysis, the cost for the OXYFINES sinter has been given the value 0 in order to calculate the sinter value at the point of addition (in Swedish currency, SEK per tonne) as a difference in cost when compared to the reference.

- The chemical composition of the OXYFINES sinter used in the modelling were an average analysis of two batches from previously performed pilot trials, Table 2 .

Table 2. Chemical analysis of the OXYFINES sinter used in the system modelling and analysis.

\begin{tabular}{cc}
\hline Content & (\%) \\
\hline $\mathrm{CaO}$ & 15.39 \\
$\mathrm{MgO}$ & 2.19 \\
$\mathrm{SiO}_{2}$ & 8.31 \\
$\mathrm{Al}_{2} \mathrm{O}_{3}$ & 5.69 \\
$\mathrm{TiO}_{2}$ & 0.45 \\
$\mathrm{~V}_{2} \mathrm{O}_{5}$ & 0.35 \\
$\mathrm{Na}_{2} \mathrm{O}$ & 0.12 \\
$\mathrm{~K}_{2} \mathrm{O}$ & 0.10 \\
$\mathrm{~S}$ & 0.02 \\
$\mathrm{P}$ & 0.11 \\
$\mathrm{Mn}$ & 0.35 \\
$\mathrm{Fe}$ & 55.13 \\
$\mathrm{C}$ & 0.09 \\
$\mathrm{Zn}$ & 0.04 \\
\hline
\end{tabular}

\section{Results}

The system analysis results indicate the effects on $\mathrm{BF}$ zinc load, raw materials consumption, energy use, and $\mathrm{CO}_{2}$ emission from using the OXYFINES sinter product as a raw material in BF ironmaking or alternatively in the BOF steelmaking processes.

\subsection{Scenario BF Results-Effects on BF Zinc Load}

The calculations on using the sinter in the BF (Scenario BF) resulted in a slight increase in the BF zinc load, from $128 \mathrm{~g} / \mathrm{tHM}$ in reference, to ca $130 \mathrm{~g} / \mathrm{tHM}$ in the analysed scenario. The slight increase in the BF zinc load in turn caused a minor increase in the zinc content of generated BF dust and sludge, Table 3.

Table 3. Blast furnace (BF) zinc load, zinc content in sinter, briquette, dust, and sludge.

\begin{tabular}{lcc}
\hline Scenario & Reference & Scenario BF \\
\hline BF zinc load (g/tHM) & 128 & 130 \\
\hline Zinc content (\%) & & \\
\hline OXYFINES sinter & - & 0.038 \\
BF briquette & 0.086 & 0.087 \\
BF dust generated & 0.250 & 0.256 \\
BF sludge generated & 1.175 & 1.201 \\
\hline
\end{tabular}




\subsection{Scenario BF Results_Effects on Charged Raw Material Amounts, HM Quality and BF Slag Rate}

The calculated results on charged BF raw materials from using the OXYFINES sinter product in the BF, compared to the reference, Figure 2, were mainly:

- A reduced consumption of iron ore pellet of ca $3.3 \mathrm{~kg} / \mathrm{tHM}$ or some $6.6 \mathrm{ktonne} / \mathrm{a}$ due to the sinter Fe content.

- A minor increase in Mn slag use, ca $0.1 \mathrm{~kg} / \mathrm{tHM}$, due to less input from charged BOF slag.

- A decreased BOF slag use in the BF with some $1.6 \mathrm{~kg} / \mathrm{tHM}$ or about $3.2 \mathrm{ktonne} / \mathrm{a}$ to prevent the phosphorous content in the HM exceeding its maximum level of $0.035 \%$.

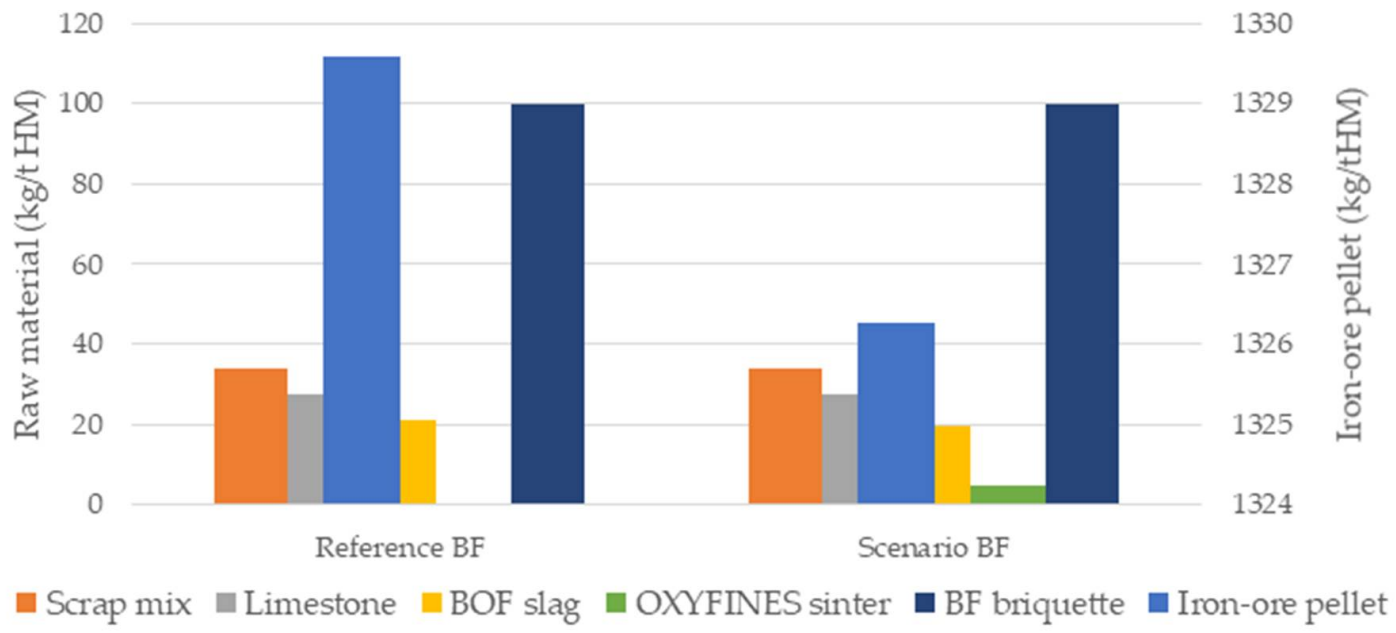

Figure 2. Results on charged BF raw materials ( $\mathrm{kg} / \mathrm{tHM})$ from using the OXYFINES sinter.

Other element contents such as sulphur in HM were unaffected by the sinter additions, only a minor decrease in vanadium content were calculated because of less BOF slag to the BF. As there was no effect on sulphur content in the HM, consequently HM desulphurisation was unaffected from the use of OXYFINES sinter in the BF.

A BF slag rate increase of some $0.4 \mathrm{~kg} / \mathrm{tHM}$ or $0.8 \mathrm{ktonne} / \mathrm{a}$ was calculated by the analysis. However, the BF slag chemical composition was essentially unaffected by the sinter additions.

\subsection{Scenario BF Results-Effects on $\mathrm{CO}_{2}$ Emission and Energy}

The scenario of using the sinter in the BF resulted in a minor $\mathrm{CO}_{2}$ emission increase of some $0.2 \mathrm{~kg} / \mathrm{tHM}$ or $0.4 \mathrm{ktonne} \mathrm{CO}_{2} / \mathrm{a}$ compared to the reference. Concerning the energy use, the total energy required in the process system increased ca $0.2 \mathrm{GWh} / \mathrm{a}$. These results are an effect of total raw materials charge and by the relative input of coal contents.

\subsection{Scenario BOF Results-Effects on Charged Raw Material Amounts, LS Quality and BOF Slag Rate}

The calculated results on charged BOF raw materials from using the OXYFINES sinter product in the BOF, compared to the reference, Figure 3, were mainly:

- A reduced consumption of iron ore pellet of ca $1.2 \mathrm{~kg} / \mathrm{tHM}$ or some $2.5 \mathrm{ktonne} / \mathrm{a}$ due to the sinter Fe content.

- A reduced HM input to the BOF of some $1.2 \mathrm{~kg} / \mathrm{tLS}$ or some $2.5 \mathrm{ktonne} / \mathrm{a}$ due to the sinter Fe content.

- A somewhat increased use of basic slag formers by ca $0.5 \mathrm{~kg}$ burnt lime/tLS and ca $0.4 \mathrm{~kg}$ dolomitic lime/tLS (roughly 1 ktonne/a of each) due to the OXYFINES sinter basicity (i.e., basicity B2 ca 1.9) and the sinter $\mathrm{CaO}$ content. 

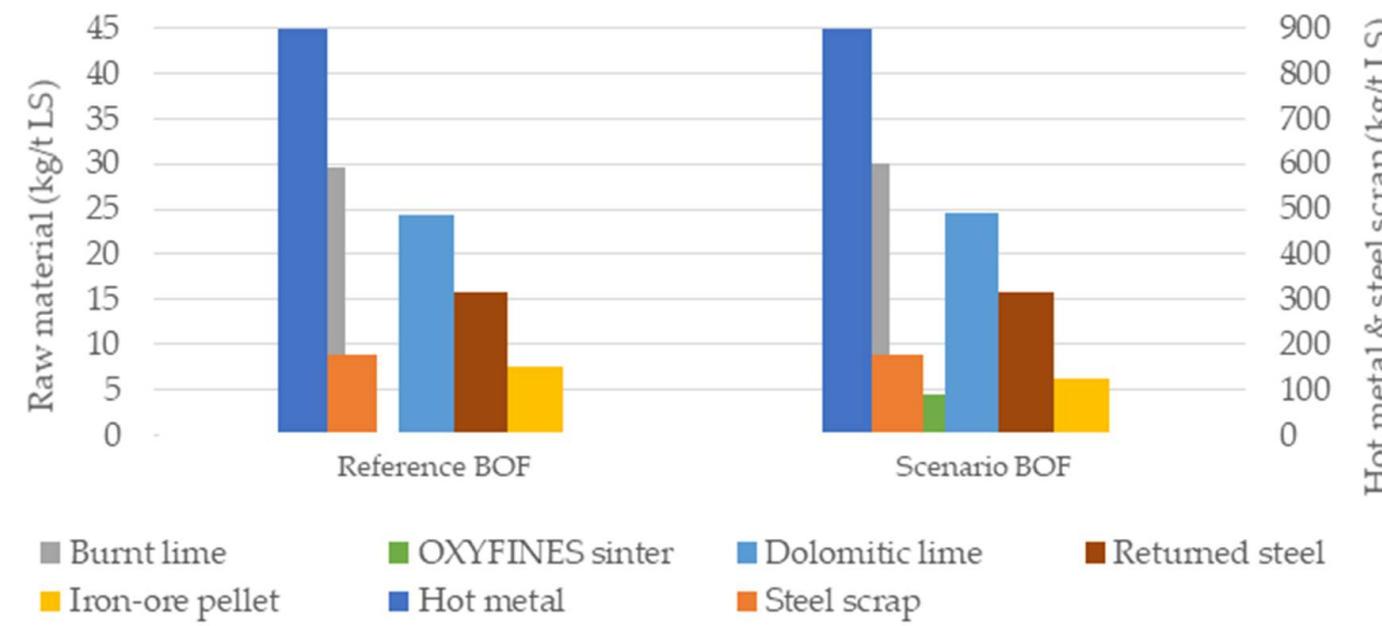

Figure 3. Results on charged BOF raw materials (kg/tLS) from using the OXYFINES sinter.

The results showed virtually no effect on LS quality from using the OXYFINES sinter. However, a BOF slag rate increase of some $3 \mathrm{~kg} / \mathrm{tLS}$ or ca $6.3 \mathrm{ktonne} / \mathrm{a}$ was calculated. The use of the OXYFINES sinter had though insignificant effects on the chemical analysis of the BOF slag.

\subsection{Scenario BOF Results-Effects on $\mathrm{CO}_{2}$ Emission and Energy}

Resulting effects on $\mathrm{CO}_{2}$ and energy from charging the OXYFINES sinter product in the BOF was a decreased total system $\mathrm{CO}_{2}$ emission by some 3.2 ktonne $\mathrm{CO}_{2} / \mathrm{a}$ and a decreased total system energy use of ca $3.6 \mathrm{GWh} / \mathrm{a}$. This result was the effect mainly by the decreased HM demand in the BOF.

\subsection{Cost Effects Calculations}

From the resulting effects, mainly on raw material use, the potential value in use of the sinter product in the separate BF and BOF processes, and on the total production system, were calculated. Decreased HM, iron ore pellet and oxygen use were the main influencing factors on the costs in the BOF scenario. Some added values are from considering the process route (i.e., $\mathrm{BF}$, deS and BOF) with the summarised effect mainly from the decreased HM demand in BOF.

Based on raw material prices and the calculated process effects mainly from the raw materials quantities used, resulted in the following approximate values for using the OXYFINES sinter:

- $669 \mathrm{SEK} /$ tonne regarding the separate BF unit and $712 \mathrm{SEK} /$ tonne considering the process route (BF, deS and BOF) in the BF scenario.

- $668 \mathrm{SEK} /$ tonne regarding the separate BOF unit and $676 \mathrm{SEK} /$ tonne considering the process route $(\mathrm{BF}, \mathrm{deS}$ and $\mathrm{BOF})$ in the BOF scenario.

For the comparison with the today's BF sludge deposit in settling ponds, based on a sludge pond deposit capacity of 50 to 70 ktonne sludge, the investment cost in a new pond is approximately 25 to 50 MSEK. If calculated for a BF sludge generation of ca 12 ktonne per year, this equals 60 ktonnes over five years production. The related sludge handling cost is estimated to some 6 MSEK per year. This results in a total cost between 916 and 1333 SEK/tonne BF sludge.

The investment costs for the separate OXYFINES process unit, based on a capacity for the recovery of 4 tonne BF sludge per hour, are roughly estimated to some 40 to 60 MSEK. The costs are, depending on the desired moisture content of the BF sludge feed for treatment, and the equipment required thereof. However, these costs are not including any surrounding buildings, pipelines for BF sludge and media or construction costs etc. Three scenarios of different moisture contents of the BF sludge feed were considered regarding a full-scale OXYFINES process for the annual upgrading of 12 ktonne BF sludge (dry weight), Table 4 . All three scenarios require sedimentation down to about $50 \mathrm{wt}$. \% moisture 
content. However, for dewatering to $35 \mathrm{wt}$. \% moisture in the sludge in scenario 2, a press filter is required. For further dewatering of the sludge, down to a moisture content of $10 \mathrm{wt}$. \% in scenario 3 , a drying furnace is additionally required.

Table 4. Scenarios of BF sludge dewatering options, moisture contents (wt. \%) and related OXYFINES consumption of LPG and $\mathrm{O}_{2}\left(\mathrm{Nm}^{3} / \mathrm{t}\right)$.

\begin{tabular}{clccc}
\hline Scenario & Dewatering Options & Moisture (wt. $\mathbf{\%})$ & LPG $\mathbf{( \mathbf { N m } ^ { 3 } / \mathbf { t } )}$ & $\mathbf{O}_{\mathbf{2}}\left(\mathbf{N m}^{\mathbf{3}} / \mathbf{t}\right)$ \\
\hline Scenario 1 & Sedimentation & 50 & 28 & 222 \\
Scenario 2 & Sedimentation + press filter & 35 & 10 & 145 \\
Scenario 3 & Sedimentation + press filter + drying furnace & 10 & 17 & 108 \\
\hline
\end{tabular}

The related calculations of LPG and $\mathrm{O}_{2}$ consumption in the OXYFINES process, based on the BF sludge moisture content, is presented in Table 4. The cost of LPG and $\mathrm{O}_{2}$ are some 4 and $1.3 \mathrm{SEK} / \mathrm{Nm}^{3}$ respectively and hence the consumption costs of LPG and $\mathrm{O}_{2}$ per tonne BF sludge are ca 400 SEK in scenario 1, ca 228 SEK in scenario 2 and 208 SEK in scenario 3.

Scenario 1 results in the lowest costs per tonne upgraded BF sludge i.e., from lesser handling and investments. However, feeding a drier sludge enables lower LPG and $\mathrm{O}_{2}$ consumption and possibilities for using excess energy e.g., for recirculating dust for zinc accumulation, and or the recovery of other iron-rich and zinc-containing, but low-coal materials.

\subsection{Summarised Material Efficiency}

The main effects on material efficiency identified from the system analysis results are summarised in Table 5. The potential for improvement in the material efficiency of the system is from the utilisation of the OXYFINES sinter, produced from the annually generated BF sludge amounts, and thus reducing the iron-ore consumption in the BF or in the BOF. In the BOF, further the HM demand was decreased as a result of the sinter use. Negative aspects in terms of the material efficiency are mainly from decreased use of BOF slag in the BF and from an increased use of basic slag formers in the BOF and hence, an increased BOF slag rate. From these results, the total material efficiency perspective is dependent on the opportunities for slag utilisation.

Table 5. Summarised results of potential material efficiency from the system analysis.

\begin{tabular}{clcc}
\hline BF & Material Efficiency Result & kg/tHM & ktonne/a \\
\hline \multirow{2}{*}{ Positive } & BF sludge upgrading and recovery in BF via OXYFINES sinter & 4.7 & 9.4 \\
& Decreased iron-ore pellet consumption & 3.3 & 6.6 \\
\hline \multirow{2}{*}{ Negative } & Decreased BOF slag use in BF & 1.6 & 3.2 \\
& Increased BF slag rate & 0.4 & 0.8 \\
\hline \multirow{2}{*}{ BOF } & & $\mathbf{k g} / \mathbf{t L S}$ & $\mathbf{k t o n n e / a}$ \\
\hline \multirow{2}{*}{ Positive } & BF sludge upgrading and recovery in BOF via OXYFINES sinter & 4.5 & 9.4 \\
& Decreased iron-ore pellet consumption & 1.2 & 2.5 \\
& Decreased HM demand in BOF & 1.2 & 2.5 \\
\hline \multirow{2}{*}{ Negative } & Increased basic slag former use in BOF & 1 & 2 \\
& Increased BOF slag rate & 3 & 6.3 \\
\hline
\end{tabular}

\subsection{Sustainability Impact Potentials}

From the system analysis results in general, the impact potential on sustainability from implementing the OXYFINES process is mainly of improved material efficiency and by the environmental perspectives of reduced need for new sludge settling ponds at the production site. The viable decrease in BF sludge to landfill or long-term storage, and thereof no need of new sludge ponds, is an essential aspect for sustainability improvement. The resulting improvements in the system 
are from upgrading and recovery of the BF sludge, by using the sinter product and thereby reducing the need of virgin raw materials, i.e., in this case mainly iron-ore pellets. However, in view of the decreased need of $\mathrm{HM}$ in the BOF, also limestone, coal and coke would be reduced.

From the system analysis calculations, the use of 1 tonne of sinter would decrease the iron ore pellet use with some 0.7 tonne in the BF and some 0.3 tonne in the BOF. In the BOF also a decreased use of HM of some 0.3 tonne is estimated.

Nevertheless, the separate OXYFINES unit process results in increased energy use and $\mathrm{CO}_{2}$ emissions through the utilisation of the BF sludge's coal content and the use of propane or coke oven gas for energy.

The risks of increased energy use and emissions by implementing the OXYFINES process are however outweighed by the overall positive effects in a life cycle perspective of the steel production and related raw materials value chain. Based on calculated heat and mass balance for BF sludge with 50 wt. \% moisture content, the resulting $\mathrm{CO}_{2}$ emissions from OXYFINES processing (i.e., from propane, and coal in BF sludge) is ca 1.5 tonnes of $\mathrm{CO}_{2}$ per tonne of product, Table 6.

Table 6. Potential $\mathrm{CO}_{2}$ effect in a holistic view from OXYFINES sinter use in the steel production.

\begin{tabular}{lc}
\hline Estimated $\mathrm{CO}_{2}$ Emissions Effects & $\mathrm{CO}_{2}$ \\
\hline OXYFINES unit sinter production (tonne $\mathrm{CO}_{2}$ /tonne sinter product) & +1.5 \\
\hline $\mathrm{HM}$ production including production of iron ore pellets (tonne $\mathrm{CO}_{2} /$ tonne HM) & 1.7 to 2.0 \\
\hline $\begin{array}{l}\text { Total from produced } \mathrm{HM} \text { and production of other raw materials used in } \mathrm{HM} \text { and LS } \\
\text { production (tonne } \mathrm{CO}_{2} / \text { tonne total) }\end{array}$ & 2.5 to 2.8 \\
\hline $\begin{array}{l}\text { Reduction in production of raw material from sinter replacing iron raw materials } \\
\text { (tonne } \mathrm{CO}_{2} / \text { tonne sinter product) }\end{array}$ & -1.0 \\
\hline Reduction by using the sinter product in the BOF (tonne $\mathrm{CO}_{2} /$ tonne sinter product) & -0.3 \\
\hline Total $\mathrm{CO}_{2}$ reduction (tonne/tonne sinter product in BOF) & -1.3 \\
\hline
\end{tabular}

Hypothetically, if considering a $\mathrm{CO}_{2}$ emission of 1.7 to 2 tonnes per tonne of $\mathrm{HM}$ produced, including $\mathrm{CO}_{2}$ from production of iron ore pellets [38], and from this, assuming a total $\mathrm{CO}_{2}$ emission of some 2.5 to 2.8 tonnes of $\mathrm{CO}_{2}$ per tonne of raw material, i.e., from the production of HM together with the $\mathrm{CO}_{2}$ for the production of other raw materials used for HM and LS production. Replacing one tonne of this total $\mathrm{CO}_{2}$ of $\mathrm{HM}$ and raw material production, with one tonne of OXYFINES sinter, thereby would result in a reduction in $\mathrm{CO}_{2}$ of some 1.0 tonnes. By using the sinter product in the $\mathrm{BOF}$, further a $\mathrm{CO}_{2}$ emission reduction of ca 0.3 tonnes per used tonne of sinter is calculated whereof a total reduction in $\mathrm{CO}_{2}$ would be about 1.3 tonne.

From this perspective, if charging the OXYFINES sinter, generated from a total of 24,000 tonnes BF sludge per year (i.e., 50\% moisture) to the BOF, this correspond to a potential annual reduced $\mathrm{CO}_{2}$ emission in the value chain by about 12,200 tonnes.

\section{Discussion}

In this research work, a system analysis case study was made based on promising results from performed pilot trials using OXYFINES technique for the recovery and upgrading of BF sludge. The approach of the study was to use process integration and a developed system analysis model with the aim to assist in the assessment of the prospects from integrating an OXYFINES concept in the steel production route. The developed system analysis model was used for indicating effects of using the OXYFINES sinter product as raw material in the iron and steel production, i.e., blast furnace or BOF.

The use of process integration, such as by system analysis and optimisation modelling, is useful for different evaluations as a complement to traditional analysis and practical tests. Nonetheless, it is important to mind that the results of the analyses are based on the inputs given to the model and is valid under the specific conditions set for the study. 
The results of the performed analysis in this work indicate the effects on BF zinc load, raw material consumption, $\mathrm{CO}_{2}$, and energy from using the sinter in the iron and steelmaking. The calculations of effects on raw materials consumption resulted mainly in a reduced iron-ore use and, regarding the BOF, a decreased demand of HM. As the OXYFINES treatment produces a virtually zinc-free sinter product, the calculations of using it in the BF showed only a minor increase in the BF zinc load. No negative effects were observed on the steel quality. However, not to exceed the maximum allowed phosphorus content in the HM required a decrease in the BOF slag recycling to the BF. An increased use of basic slag formers in the BOF were calculated and hence, an increased BOF slag rate for which the total material efficiency perspective is dependent on opportunities for slag utilisation. From the outcome of this study, the overall material efficiency and sustainability in the production system would be enhanced by the upgrading of the BF sludge and using the OXYFINES sinter in the iron and steel production route, thus reducing the BF sludge to deposits.

The summarised system analysis results showed that the most advantageous metallurgical, environmental, and economic potential was realised in the calculations of using the sinter in the BOF. However, the sinter was found also to be suitable for use in the blast furnace when considering mainly the metallurgical and the economic effects.

For the improved understanding and for optimising the metallurgical properties of the sinter, a more fundamental study is required, focusing on material characteristics and thermodynamic calculations linked to the control parameters of the OXYFINES process. Through this, a deeper understanding and knowledge can be obtained to identify optimal process conditions for efficiently generating specified products for their intended use.

The results of this study are based on a BF sludge moisture content of 50\%. However, the OXYFINES unit process energy use and $\mathrm{CO}_{2}$ emissions can be improved e.g., by optimising the moisture content in the BF sludge prior to feeding, optimising the OXYFINES process efficiency, and using coke oven gas alternatively natural gas or hydrogen as energy source for the process. Further possibilities are by utilising the heat in the cooling water used for the OXYFINES process, and the hot exhaust gases, e.g., for drying material (sludge), which would further benefit the sustainable aspects of the concept.

The prospects of a full-scale OXYFINES concept are motivated by sinter product value and by comparing costs and environmental effects with the todays deposit of the BF sludge in settling ponds. The investment costs per tonne of BF sludge depends on desired moisture content of the BF sludge feed and is decreased with less dewatering. However, considering a BF sludge feed of lower moisture content, this would in addition generate an excess energy which is possible to utilise for an extended treatment also of other iron-rich and zinc-containing, but low-coal materials, thereby further improving the $\mathrm{CO}_{2}$ mitigation perspective.

\section{Conclusions}

The performed system analysis case study aimed to assist in the assessment of the prospects from integrating an OXYFINES concept in the steel production route by indicating effects of using the OXYFINES sinter product as raw material in the iron and steel production. From the results of the study the following conclusions were drawn:

- Implementation of the OXYFINES concept has positive effects on sustainability mainly by improved material efficiency and by waste prevention.

- The recovery of blast furnace sludge decreases landfill and using generated OXYFINES products contributes to the value chain by reduced need for virgin raw materials.

- The risks of increased energy use and $\mathrm{CO}_{2}$ emissions by implementing the OXYFINES concept can be outweighed by the overall positive sustainability effects in a life cycle perspective. In view of a holistic perspective, the effects on $\mathrm{CO}_{2}$ emissions and energy use in the steel production system, also in the production of raw materials should be considered. 
- An industrial implementation contributes to a sustainable energy and material supply by developing the technology to optimally utilise and refine valuable components in residual materials.

- The holistic system analysis results showed that the most beneficial metallurgical, environmental, and economic potential was found when using the sinter in the BOF. However, the sinter was found as well suitable for use in the blast furnace when considering mainly the metallurgical and the economic effects.

Author Contributions: Conceptualisation, all authors (F.N., K.B., L.G., D.S., A.W., K.L. and S.R.); methodology, all authors; software, K.L. and S.R.; validation, F.N., K.B., L.G., D.S., A.W.; formal analysis, K.L.; investigation, all authors; data curation, F.N., K.B., A.W., S.R. and K.L.; writing-original draft preparation, K.L.; writing-review and editing, K.L.; visualization, all authors; project administration, K.L.; funding acquisition, K.L. All authors have read and agreed to the published version of the manuscript.

Funding: This research was funded by the Swedish Energy Agency via the strategic innovation programme RE: Source, and the specific call: Innovations for sustainable material use: Development and demonstration. Additional funding was made via the Centre for Process Integration in Metallurgy (PRISMA), at the time of the research work located at Swerim AB. The Centre was supported by its industrial participants, including SSAB Europe, SSAB Merox and Linde Gas AB.

Acknowledgments: The work presented in this paper was developed within the project "Optimised sludge recycling using OXYFINES technique", Optifines (project number: 46112-1), which has received funding by the Swedish Energy Agency-Energimyndigheten via RE: Source. Additional funding was contributed by the Centre for Process Integration in Metallurgy (PRISMA) and the work was supported by the industrial partners of the project including Linde Gas AB, SSAB Europe, SSAB Merox and Boliden Mineral AB.

Conflicts of Interest: The authors declare no conflict of interest.

\section{References}

1. UN Sustainable Development Goals. Available online: https://www.un.org/sustainabledevelopment/ sustainable-development-goals/ (accessed on 4 April 2019).

2. EU Circular Economy Package. Available online: http://ec.europa.eu/environment/circular-economy/index_ en.htm (accessed on 4 April 2019).

3. Lundkvist, K.; Brämming, M.; Hagemalm, J.; Lagerwall, P.; Wedholm, A. Case study of reclaiming zinc containing sludge from settling ponds. In Proceedings of the 8th International Congress on Science and Technology of Ironmaking-ICSTI, Vienna, Austria, 25-28 September 2018.

4. Makkonen, H.T.; Heino, J.; Laitila, L.; Hiltunen, A.; Poylio, E.; Harkki, J. Optimisation of steel plant recycling in Finland: Dusts, scales and sludge. Resour. Conserv. Recycl. 2002, 35, 77-84. [CrossRef]

5. Koros, P.J. Dusts, Scale, Slags, Sludges Not Wastes, But Sources of Profits. Metall. Mater. Trans. B 2003, 34, 769-778. [CrossRef]

6. Branca, T.A.; Colla, V.; Algermissen, D.; Granbom, H.; Martini, U.; Morillon, A.; Pietruck, R.; Rosendahl, S. Reuse and Recycling of By-Products in the Steel Sector: Recent Achievements Paving the Way to Circular Economy and Industrial Symbiosis in Europe. Metals 2020, 10, 345. [CrossRef]

7. Von Schéele, J. OXYFINES ${ }^{T M}$ technology for the re-melting of fines, dust and sludge. In Proceedings of the 10th International Ferroalloys Congress, Cape Town, South Africa, 1-4 February 2004.

8. Jalkanen, H.; Oghbasilasie, H.; Raipala, K. Recycling of Steelmaking Dusts-The Radust Concept. J. Min. Metall. 2005, 41, 1-16. [CrossRef]

9. Lundkvist, K.; Rosendahl, S.; Nyman, F.; Bölke, K.; Gustavsson, L.; Söderström, D.; Wedholm, A. Oxyfines technique for upgrading zinc containing blast furnace sludge-Part 1: Pilot trials. Metals. 2020, 10, 1468. under review.

10. Smith, R. State of the art in process integration. Appl. Therm. Eng. 2000, 20, 1337-1345. [CrossRef]

11. El-Halwagi, M.M. Process Integration; Elsevier Science: Amsterdam, The Netherlands, 2006; ISBN 9780080454290.

12. Bradley, S.P.; Hax, A.C.; Magnanti, T.L. Applied Mathematical Programming; Addison-Wesley: Boston, MA, USA, 1977; ISBN 020100464X. 
13. Dutta, G.; Fourer, R. A Survey of Mathematical Programming Applications in Integrated Steel Plants. Manuf. Serv. Oper. Manag. 2001, 3, 387-400. [CrossRef]

14. Grossmann, I.E.; Guillén-Gosálbez, G. Scope for the Application of Mathematical Programming Techniques in the Synthesis and Planning of Sustainable Processes. Comput. Chem. Eng. 2010, 34, 1365-1376. [CrossRef]

15. Dutta, G.; Fourer, R. An Optimization-Based Decision Support System for Strategic and Operational Planning in Process Industries. Optim. Eng. 2004, 5, 295-314. [CrossRef]

16. Natural Resources Canada. Pinch Analysis: For the Efficient Use of Energy, Water E Hydrogen; Catalogue \# M39-96/2003E; Natural Resources Canada: Ottawa, ON, Canada, 2003; ISBN 0-662-34964-4.

17. McBrien, M.; Cabrera Serrenho, A.; Allwood, J.M. Potential for energy savings by heat recovery in an integrated steel supply chain. Appl. Therm. Eng. 2016, 103, 592-606. [CrossRef]

18. Matsuda, K.; Tanaka, S.; Endou, M.; Iiyoshi, T. Energy saving study on a large steel plant by total site based pinch technology. Appl. Therm. Eng. 2012, 43, 14-19. [CrossRef]

19. Measuring Material Flows and Resource Productivity, Volume I. The OECD Guide. 2008. Available online: http://www.oecd.org/environment/indicators-modelling-outlooks/MFA-Guide.pdf (accessed on 20 September 2020).

20. Park, J.-A.; Hong, S.-J.; Kim, I.; Lee, J.-Y.; Hur, T. Dynamic material flow analysis of steel resources in Korea. Resour. Conserv. Recycl. 2011, 55, 456-462. [CrossRef]

21. Yellishetty, M.; Ranjith, P.G.; Tharumarajah, A. Iron ore and steel production trends and material flows in the world: Is this really sustainable? Resour. Conserv. Recycl. 2010, 54, 1084-1094. [CrossRef]

22. Caffrey, K.R.; Chinn, M.S. Life Cycle Assessment (LCA): Description and Methodology; North Carolina A\&T State University: Greensboro, NC, USA, 2015.

23. Guinée, J.B.; Heijungs, R.; Huppes, G.; Zamagni, A.; Masoni, P.; Buonamici, R.; Ekvall, T.; Rydberg, T. Life Cycle Assessment: Past, Present, and Future. Environ. Sci. Technol. 2011, 45, 90-96. [CrossRef]

24. Burchart-Korol, D. Significance of Environmental Life Cycle Assessment (LCA) Method in the Iron and Steel Industry. Metalurgija 2011, 50, 205-208.

25. Olmez, G.M.; Dilek, F.B.; Karanfil, T.; Yetis, U. The environmental impacts of iron and steel industry: A life cycle assessment study. J. Clean. Prod. 2016, 130, 195-201. [CrossRef]

26. Weiss, B.; Spanlang, A.; Wukovits, W. Primetals Technologies GmbH Strategic operation and raw materials planning for integrated steel plants in the process integration platform m.simtop. In Proceedings of the 8th International Congress on Science and Technology of Ironmaking ICSTI, Vienna, Austria, 25-27 September 2018.

27. Schultmann, F.; Engels, B.; Rentz, O. Flowsheeting-based simulation of recycling concepts in the metal industry. J. Clean. Prod. 2004, 12, 737-751. [CrossRef]

28. Chen, B.; Yang, J.; Ouyang, Z. Life Cycle Assessment of Internal Recycling Options of Steel Slag in Chinese Iron and Steel Industry. J. Iron Steel Res. 2011, 18, 33-40. [CrossRef]

29. Spengler, T.; Geldermann, J.; Htihre, S.; Sieverdingbeck, A.; Rentz, O. Development of a multiple criteria based decision support system for environmental assessment of recycling measures in the iron and steelmaking industry. J. Clean. Prod. 1998, 6, 37-52.

30. Fröhling, M.; Rentz, O. A case study on raw material blending for the recycling of ferrous wastes in a blast furnace. J. Clean. Prod. 2010, 18, 161-173. [CrossRef]

31. Tang, J.; Liu, Y.; Fung, R.Y.K.; Luo, X. Industrial waste recycling strategies optimization problem: Mixed integer programming model and heuristics. Eng. Optim. 2008, 40, 1085-1100. [CrossRef]

32. Ryman, C.; Grip, C.-E.; Larsson, M. Model based evaluation of sustainability indicators in integrated steelmaking: A Swedish case study. In Proceedings of the AISTech 2007, Indianapolis, IN, USA, 7-10 May 2007.

33. Larsson, M. Analysis and Optimisation of Energy and Environmental Performance of an Integrated Steel Plant by Process Integration. Licentiate Thesis, Luleå University of Technology, Luleå, Sweden, 2003.

34. Andersson, A.; Gullberg, A.; Kullerstedt, A.; Sandberg, E.; Andersson, M.; Ahmed, H.; Sundqvist-ökvist, L.; Björkman, B. A holistic and experimentally-based view on recycling of off-gas dust within the integrated steel plant. Metals 2018, 8, 760. [CrossRef]

35. Matino, I.; Branca, T.A.; Fornai, B.; Colla, V.; Romaniello, L. Scenario Analyses for By-Products Reuse in Integrated Steelmaking Plants by Combining Process Modeling, Simulation, and Optimization Techniques. Steel Res. Int. 2019, 90, 1900150. [CrossRef] 
36. Lundkvist, K. A Process Integration Approach to Assessing Possibilities for Improved Material Efficiency in Nordic Ore-Based Iron- and Steelmaking Systems. Licentiate Thesis, Luleå University of Technology, Luleå, Sweden, 2019.

37. Hooey, P.L.; Bodén, A.; Wang, C.; Grip, C.-E.; Jansson, B. Design and Application of a Spreadsheet-based Model of the Blast Furnace Factory. ISIJ Int. 2010, 50, 924-930. [CrossRef]

38. LKAB. Our Iron Ore Pellets for Purer Steel. Available online: https://www.lkab.com/en/sustainability/ environment/energy-and-climate/our-iron-ore-pellets-for-purer-steel/ (accessed on 21 October 2020).

Publisher's Note: MDPI stays neutral with regard to jurisdictional claims in published maps and institutional affiliations.

(C) 2020 by the authors. Licensee MDPI, Basel, Switzerland. This article is an open access article distributed under the terms and conditions of the Creative Commons Attribution (CC BY) license (http://creativecommons.org/licenses/by/4.0/). 